\title{
Cornell Announces Results of 2004 Materials Images Competition
}

The Materials Research Society's Student Chapter at Cornell University, in collaboration with Cornell's Department of Materials Science and Engineering (MSE), announced the results of its third annual Microscopy Image Competition:
Images in the Material World. Three awards were given in each of two categories: most scientifically significant image and most artistic image. Prizes of digital cameras were provided by the Eastman Kodak Company.

The competition was promoted to undergraduate students in the United States and Canada. Entries were judged by Cornell MS\&E professor Christopher Ober. More information on the contest is available at Web site www.mse.cornell.edu.

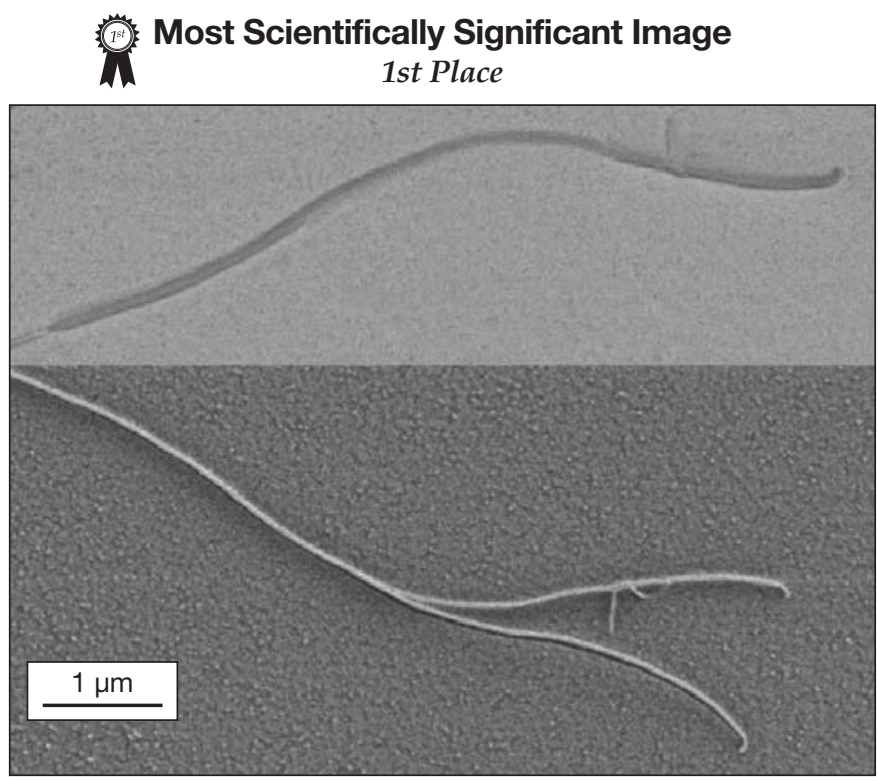

\section{Carbon Nanotube Lithography}

Craig S. Terry, University of Washington, Seattle

Imaging: Scanning electron microscope

Description: The top half of the image is an imprint in 100-nm-thick poly(methyl methacrylate) of a multiwalled carbon nanotube on a Si substrate, briefly reactive-ion-etched, and coated with Teflon; the bottom half is the stamp that made the imprint. Note that the nanotube has separated from its base during mold release.

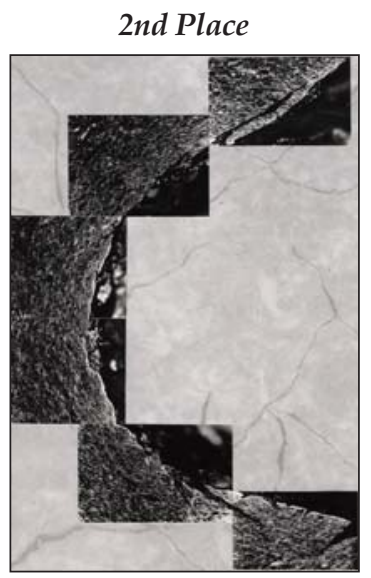

\section{Crater}

Christina Pina

University of Texas at El Paso

Imaging: Optical microscope Description: Projectile impact on a piece of stainless steel at $3.4 \mathrm{~km} / \mathrm{s}$. The crater was then cut in half, polished, and electronically etched.

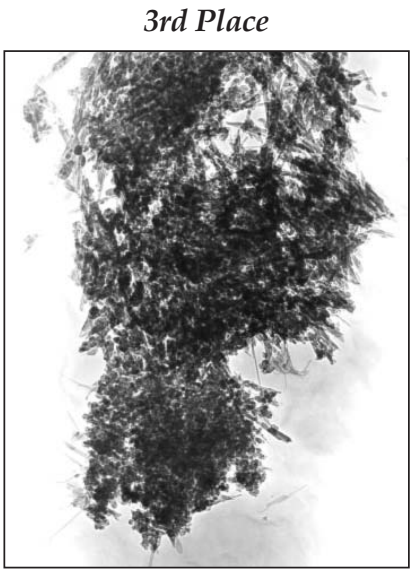

The Nanotube Mother

Priscilla A. Guerrero

University of Texas at El Paso

Imaging: Transmission electron microscope

Description: Aggregate of carbon nanotubes collected from an El Paso power plant.

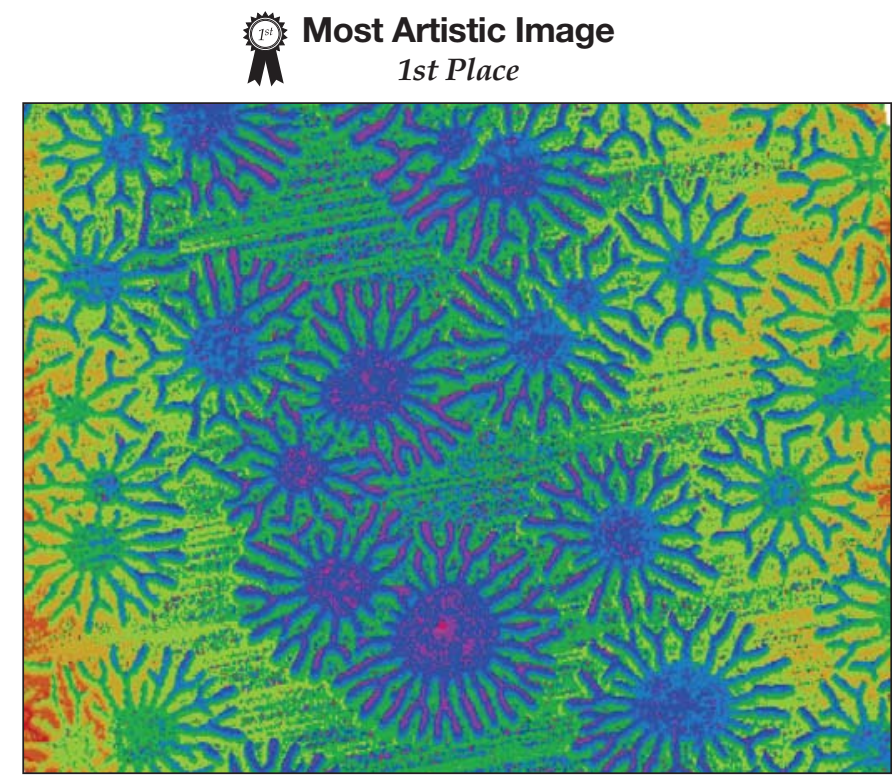

\section{Lead Snowflakes}

Dale Anderson, Michigan Technological University

Imaging: Single-beam atomic force microscope

Description: The "snowflakes" are the result of lead condensing around impurities on a single-crystal silicon substrate. The growth mechanism is believed to be vapor condensation, and the image is presented in falsecolor height mode. The width of the image is $60 \mu \mathrm{m}$.

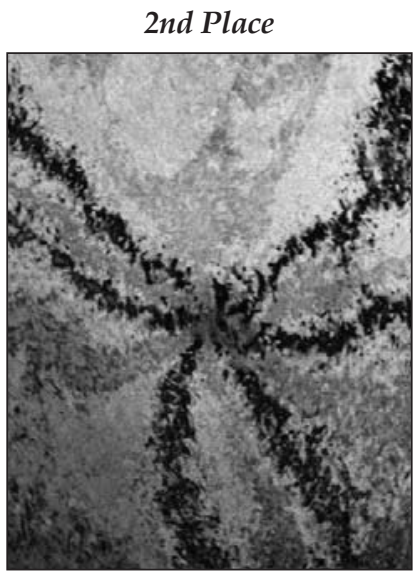

\section{Tarantalum}

Kate Jackson

Cornell University

Imaging: Scanning transmission electron microscope

Description: Tantalum thin film on a silicon substrate.

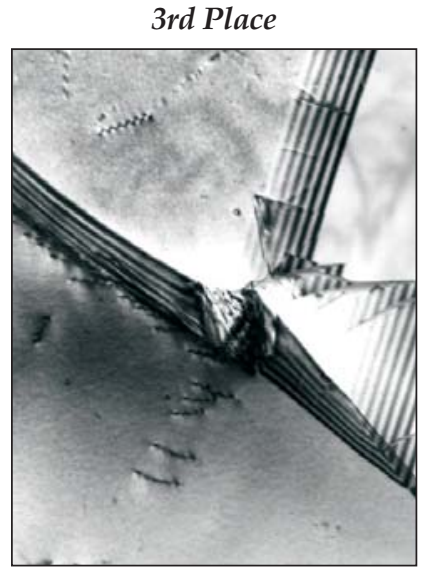

316

Daniel E. Bujanda, University of Texas at El Paso

Imaging: Transmission electron microscope

Description: A sample of 316L stainless steel used in forming a Caribbean steel drum. 